\title{
Avaliação histológica e por microscopia eletrônica de varredura da biocerâmica de fosfato de cálcio nano-estruturada micromacro porosa em grânulos em defeito crítico de rádio de coelhos
}

\author{
[Histological and nano-structured calcium phosphate bioceramic micro-macro porous granules \\ in critical defect rabbits radius scanning electron microscopy evaluation] \\ O.L.P. Aristizabal ${ }^{1}$, J.A.V. Castro $^{2}$, M.I.V. Vargas $^{3}$, C.M.F. Rezende ${ }^{2}$ \\ ${ }^{1}$ Facultad de Medicina Veterinaria y Zootecnia Universidad del Tolima \\ ${ }^{2}$ Escola de Veterinária - Universidade Federal de Minas Gerais - Belo Horizonte, MG \\ ${ }^{3}$ Universidade Federal de Viçosa - UFV - Viçosa, MG
}

\begin{abstract}
RESUMO
Objetivou-se avaliar, histologicamente e por microscopia eletrônica de varredura (MEV), a evolução de defeitos críticos experimentais em rádio de coelhos preenchidos ou não com biocerâmica fosfocálcica nanoestruturada micromacro porosa em grânulos. Utilizaram-se 70 coelhos, Nova Zelândia, adultos jovens, machos, e realizou-se um defeito crítico nos rádios. Os membros constituíram os grupos: GI, biocerâmica lenta, GII, biocerâmica moderada e GIII, controle negativo. Após cada período experimental, os animais foram sacrificados, e os rádios coletados. As avaliações histológicas foram realizadas aos oito, 15, 30, 45, 60, 90 e 120 dias, e as análises de MEV aos 60, 90 e 120 dias. Histologicamente, observou-se processo de reparação óssea mais adiantado nos grupos GI e GII comparando-se ao GIII. Na MEV, constatou-se maior proporção de osso maduro e presença de ósteons secundários nos GI e GII, sendo mais evidente no GII, confirmando os achados histológicos. As cerâmicas promoveram preenchimento completo do defeito, enquanto no grupo controle houve preenchimento no centro do defeito, permanecendo espaços vazios nas laterais. Conclui-se que o emprego das biocerâmicas de absorção lenta e moderada favorece a regeneração óssea completa em defeitos críticos sendo indicadas como substituto ósseo. A maturação óssea ocorre mais precocemente quando se emprega a cerâmica de absorção moderada.
\end{abstract}

Palavras-chave: defeito crítico, hidroxiapatita, fosfato de cálcio, radio

\begin{abstract}
The objective was to evaluate, through histologic exam and by scanning electron microscopy (SEM), the evolution of experimental critical defects in radio or not filled with nano-structured calcium phosphate micro-macro porous bioceramic granules rabbits. We used 70 rabbits, New Zealand, young adults, males, there was a critical defect in radio. The members were the groups: GI, slow bioceramic, GII, GIII and bioceramic moderate, negative control. After each experimental period, the animals were sacrificed and the radios harvested. Histological evaluations were performed at eight, 15, 30, 45, 60, 90 and 120 days and SEM analyzes at 60, 90 and 120 days. Histologically there was bone healing process earlier in GI and GII compared to GIII. In SEM we observed a higher proportion of mature bone and presence of secondary osteons in GI and GII, being more evident in the GII, confirming the histological findings. Ceramic promoted complete filling of the defect, while the control group was filling in the center of the defect, with empty spaces remaining on the sides. In conclusion, the use of bioceramics, slow and moderate absorption favor complete bone regeneration in critical defects being indicated as a bone substitute. The maturation occurs earlier when employing the ceramic moderate absorption.
\end{abstract}

Keywords: critical defect, hydroxyapatite, calcium phosphate, radio

Recebido em 19 de junho de 2016

Aceito de 6 de janeiro de 2017

E-mail: omarlap@msn.com 


\section{Aristizabal et al.}

\section{INTRODUÇÃO}

O osso é um compósito mineralizado que apresenta diversos tipos celulares associados a uma fração mineral e a uma biopolimérica. A fração mineral é composta basicamente por cristais de apatita que se assemelham à hidroxiapatita (HA) e que contêm, em menores proporções, outros minerais, como carbonato (CO3), magnésio $(\mathrm{Mg})$ e sódio $(\mathrm{Na})$. A fração biopolimérica é composta por proteínas da matriz extracelular, onde se observa predominância de colágeno tipo I, além de outras proteínas não colagenosas, como osteopontina, fibronectina, sialoproteína óssea e proteínas ósseas morfogenéticas (LeGeros, 2008).

A pesquisa por substitutos ósseos data da PréHistória, e grandes esforços ainda são direcionados para a elaboração de substitutos sintéticos que possam proporcionar resultados semelhantes ou superiores aos enxertos autólogos (Caplan e Goldberg, 1999; Betz, 2002). A bioengenharia de tecidos, que aplica princípios de biologia, química, matemática, física e engenharia, tenta reproduzir processos biológicos básicos que ocorrem durante a regeneração tecidual, para que se possa obter uma recuperação funcional do esqueleto humano (Caplan e Goldberg, 1999).

Entre os biomateriais sintéticos que apresentam potencial para serem utilizados como matrizes carreadoras de células-tronco, estão as biocerâmicas bifásicas de fosfatos de cálcio (BCP), devido à sua semelhança química com o osso, à bioatividade e à biocompatibilidade. Algumas biocerâmicas têm sido consideradas também osteoindutoras e não apenas osteocondutoras, como a maioria dos biomateriais sintéticos (Wykrota et al., 2000; LeGeros, 2008). Além disso, a diversidade e a versatilidade de formas de apresentação, assim como a possibilidade de se obterem biomateriais com distintas composições químicas e estruturas físicas, fazem das biocerâmicas bifásicas uma vantajosa alternativa para cirurgias ortopédicas, de crânio e bucomaxilofaciais (Oliveira et al., 2007; LeGeros, 2008).

Algumas biocerâmicas bifásicas de fosfatos de cálcio são capazes de promover a regeneração óssea com sucesso, de pacientes portadores de defeitos ortopédicos cavitários de diversas magnitudes e em distintas localizações, assim como de defeitos ósseos (Wykrota et al., 2000). Sabe-se que a evolução clínica de cada paciente é dependente não apenas do tipo de substituto ósseo utilizado, mas também de suas condições gerais, como idade e doenças associadas e da técnica cirúrgica utilizada. No que diz respeito aos biomateriais, as respostas teciduais são diretamente dependentes de sua composição química e de suas características físicas. Biomateriais que diferem em um ou mais desses quesitos levarão inevitavelmente a distintas respostas locais e, logo, a diferentes evoluções clínicas (Wykrota et al., 2000; Lobo, 2011).

As limitações do emprego do enxerto biológico têm impulsionado as pesquisas com biomateriais capazes de favorecer o crescimento ósseo por condução e, se possível, por indução. Essas características, dependentes das propriedades físicas e químicas do material, devem ser compatíveis com a fisiologia óssea Devido a suas propriedades físicas e estruturais, a biocerâmica de fosfatos de cálcio nanoestruturada micromacro porosa mostra-se como alternativa para uso em diferentes situações, uma vez que favorece a reparação óssea em fraturas recentes, crônicas e é usada também para preenchimento de falhas ósseas nos casos de prótese articular. É uma alternativa viável, disponível na quantidade desejada, economicamente viável e compatível com o tecido ósseo, visto que sua estrutura é semelhante a do osso (Gao et al., 1995). O biomaterial deve ser degradável, para não interferir nas propriedades mecânicas do osso neoformado, e possuir poros interconectados de diâmetro entre 100 e $500 \mu \mathrm{m}$ (Rumpel et al., 2006). A conexão entre os poros facilita a invasão de células e vasos sanguíneos. As desvantagens do material poroso, entretanto, são a dificuldade de uniformidade dos poros e a susceptibilidade de desintegração e consequente perda de função (Shimazaki e Mooney, 1985).

A biocerâmica de fosfato de cálcio bifásica micromacro porosa nanoestruturada, composta de $65 \%$ de HA e $35 \%$ de $\beta$-TCP, foi utilizada por Lobo et al. (2009) para preencher defeito de $5 \mathrm{~mm}$ de diâmetro no fêmur de coelhos Nova Zelândia, machos, adultos, seguindo-se avaliações por 90 dias. Os achados histológicos mostravam, aos 15 dias, tecido ósseo em torno e dentro dos grânulos da biocerâmica nas regiões cortical e medular. Havia, aos 30 dias, maior 
organização do osso compacto e manutenção do mesmo padrão de distribuição, apesar da presença de células adiposas circundando o complexo. Aos 90 dias, verificou-se maior quantidade de tecido adiposo e de tecido ósseo bem organizado em torno e dentro dos grânulos. No grupo sem biocerâmica, os autores observaram, aos 15 dias, na cortical, defeito preenchido por coágulo que mostrava ilhas de tecido ósseo sem orientações, com muitos vasos sanguíneos no tecido adiposo, na região medular. Aos 30 dias, a região cortical apresentava camadas interrompidas de tecido ósseo. $\mathrm{O}$ padrão foi mantido aos 90 dias, com tecido adiposo ocupando parte da região cortical.

Lobo et al. (2009) e Lobo e Arinzeh (2010) relataram presença de canais de Havers e osteócitos dispostos longitudinalmente ao longo do osso, enquanto o canal medular era completamente composto por tecido adiposo. Aos 15 dias, o grupo controle mostrava defeitos preenchidos por coágulo sanguíneo, com pequenas ilhas de tecido ósseo sem nenhuma orientação definida na região cortical e muitos vasos sanguíneos na região medular. Aos 30 dias, a região cortical apresentava uma camada contínua de tecido ósseo. Esse padrão foi mantido até os 90 dias, com o tecido adiposo ocupando parte da região cortical. No grupo tratado, aos 15 dias, foi observado tecido ósseo em volta e no interior dos grânulos de cerâmica, em regiões corticais e medulares. Aos 30 dias, as amostras apresentaram um padrão de tecido ósseo compacto mais organizado na região cortical. No canal medular, o tecido ósseo se manteve com o mesmo padrão de distribuição (na periferia e dentro dos grânulos). Aos 90 dias, observou-se mais tecido adiposo na região medular, mas foi observado também tecido ósseo bem organizado ao redor e dentro dos grânulos inteiros da biocerâmica.

Assim, o objetivo deste estudo foi avaliar, por exames histológicos e de microscopia eletrônica de varredura, o efeito da HA/ßTCP de absorção lenta e moderada, após seu emprego em defeito crítico em rádio de coelhos.

\section{MATERIAL E MÉTODOS}

Este trabalho foi aprovado pelo Comitê de Ética em Experimentação Animal (Cetea) da Universidade Federal de Minas Gerais, como consta no protocolo $\mathrm{n}^{\mathrm{o}}$ 275/2010. Foram utilizados 70 coelhos (Oryctolagus cuniculus) da raça Nova Zelândia, brancos, machos, adultos jovens, com massa corporal média de 2,5 $3,0 \mathrm{~kg}$. Os animais foram mantidos por duas semanas, em gaiolas individuais de arame galvanizado medindo $60 \times 60 \times 37 \mathrm{~cm}$, no Laboratório de Metabolismo Animal da Escola de Veterinária da UFMG, quando foram avaliados mediante exame clínico geral e laboratorial (hemograma) e submetidos a avaliações radiográficas de controle.

No pré-operatório, os coelhos receberam, pela via intravenosa, $30 \mathrm{mg} / \mathrm{kg}$ de cefalotina como antibiótico profilático, 30 minutos antes do procedimento. A anestesia foi induzida com injeção intramuscular, na região glútea, de $20 \mathrm{mg} / \mathrm{kg}$ de cloridrato de cetamina e $2,5 \mathrm{mg} / \mathrm{kg}$ de cloridrato de xilazina. Logo após, foi feita a tricotomia ampla dos membros torácicos direito e esquerdo desde a região da escápula até a articulação metacarpofalangeana. Para a manutenção anestésica, foi utilizada anestesia inalatória com isoflurano, dose de manutenção de 1-3\%, segundo a necessidade. Durante todo o período anestésico, foram monitoradas as freqüências cardíaca e respiratória. Fluidoterapia de apoio foi feita com solução de cloreto de sódio a $0,9 \%$. A terapia analgésica foi realizada com morfina, em dose de $2-5 \mathrm{mg} / \mathrm{kg}$, a cada quatro horas, durante três dias.

Uma vez posicionados em decúbito esternal com os membros anteriores estendidos, foi realizada antissepsia dos membros anteriores direito e esquerdo com solução de iodopolivinilpirrolidona (PVPI) degermante, seguida por solução alcoólica de iodo a $2 \%$ desde a articulação escapuloumeral até a articulação metacarpofalangeana, seguindo-se a colocação dos panos de campo.

A abordagem ao rádio foi feita segundo preconizado por Piermattei e Flo (2004). Realizou-se a mensuração do fragmento a ser removido, que consistiu de duas vezes e meia o diâmetro do terço médio do rádio. Após a realização da ostectomia, procedeu-se à execução da sutura de cada um dos diferentes planos cirúrgicos (fáscia, subcutâneo e pele). A fáscia e o tecido subcutâneo foram aproximados com fios absorvíveis de ácido poliglicólico 5-0 em padrão contínuo simples, e a dermorrafia foi realizada 
por pontos simples separados com náilon monofilamentar 5-0. Em ambos os rádios operados, foi feita uma bandagem de proteção com atadura elástica cobam (3M), como proteção local da cirurgia, minimizando riscos de contaminação. Após as cirurgias, os animais foram mantidos em gaiolas individuais de 60x60x37cm, no Laboratório de Metabolismo Animal da Escola de Veterinária da UFMG. Foram realizadas avaliações clínicas diariamente durante os 10 primeiros dias, tempo no qual foram observados aumento de volume, temperatura local, estabilidade óssea e deambulação.

Os animais foram divididos em três grupos experimentais constituídos pelos membros operados em grupo I (GI) e grupo II (GII), cujos defeitos foram preenchidos respectivamente com a biocerâmica de fosfato de cálcio nanoestruturada micromacro porosa em grânulos de 40 a 60 mesh, de absorção lenta e modera e, grupo III (GIII), controle, permanecendo o defeito vazio. As cerâmicas foram produzidas e gentilmente cedidas pela empresa EINCO Biomaterial Ltda. (Belo Horizonte, Minas Gerais, Brasil).

A análise do osso por microscopia eletrônica de varredura foi limitada aos tempos finais do estudo, 60, 90 e 120 dias, e as imagens foram analisadas no Centro de Microscopia da UFMG e comparadas com as obtidas na microscopia óptica. Os animais foram submetidos à eutanásia por sobredose anestésica com tiopental sódico, após sedação com $40 \mathrm{mg} / \mathrm{kg}$ de cloridrato de cetamina, e seguiu-se a coleta de amostras ósseas, que foram processadas seguindo-se os protocolos desenvolvidos no CM-UFMG.

As amostras constituíram-se de fragmentos ósseos do rádio direito e esquerdo, de cerca de $2 \mathrm{~cm}$ de comprimento, compreendendo a região do defeito $(1 \mathrm{~cm})$ e $0,5 \mathrm{~cm}$ além das linhas de osteotomia proximal e distal. As amostras foram acondicionadas em placa de 12 wells e cobertas com fixador primário modificado: *Karnovsky $(2,0 \%$ para formaldeído e $2,5 \%$ para glutaraldeído), em tampão fosfato $0,1 \mathrm{M}$, overnight. O fixador foi removido e as amostras foram lavadas três vezes (10 minutos) em tampão fosfato $0,1 \mathrm{M}$. Em seguida, foi realizada a pós-fixação das amostras no fixador secundário $^{* *}$ por uma hora; (**tetróxido de ósmio 1,0\%). Logo depois, elas foram lavadas novamente por três vezes (10 minutos) em tampão fosfato $0,1 \mathrm{M}$. Posteriormente, procedeu-se à imersão das amostras em ácido tânico $1 \%$ em tampão fosfato $0,1 \mathrm{M}$ por 20 minutos. Imediatamente após, foram lavadas novamente por três vezes (10 minutos) em tampão fosfato $0,1 \mathrm{M}$, seguindo-se a imersão no fixador secundário** por uma hora; (**tetróxido de ósmio 1,0\%). Imediatamente após, as amostras foram lavadas por três vezes (10 minutos) em água destilada. Uma vez lavadas, as amostras foram desidratadas em solução crescente de álcool etílico 35\%, 50\%, $70 \%, 85 \%, 95 \%$ (10 minutos) e $100 \%$ (três vezes -10 minutos). Seguiu-se, então, a secagem das amostras no ponto crítico de $\mathrm{CO}^{2}$, utilizando-se a mesma metodologia já descrita anteriormente para a microscopia eletrônica da biocerâmica.

As avaliações histológicas foram realizadas aos oito (tempo 1), 15 (tempo 2), 30 (tempo 3), 45 (tempo 4), 60 (tempo 5), 90 (tempo 6) e 120 dias (tempo 7).

Após a remoção dos tecidos moles, o terço médio do rádio foi coletado numa extensão de cerca de $5 \mathrm{~mm}$ além do defeito ósseo. Esse material foi fixado por 48 horas em formalina a $10 \%$ tamponada. Posteriormente, cada fragmento foi envolvido em gaze e identificado para descalcificação em ácido fórmico a $50 \%$, durante 20 dias. A solução era trocada a cada 48 horas até a comprovação radiográfica de completa descalcificação do tecido.

Após a descalcificação, as amostras foram lavadas por 24 horas em água corrente, foram posteriormente desidratadas em álcoois de concentrações crescentes $(70 \%, 80 \%, 90 \%$, absoluto 1, absoluto 2), permanecendo duas horas em cada um deles. Após a desidratação, os fragmentos foram diafanizados em xilol por duas horas, embebidos em parafina líquida por duas horas e incluídos em blocos de parafina. As amostras foram coradas com hematoxilina-eosina segundo o procedimento padrão para observação por microscopia óptica de luz.

A análise das amostras foi realizada no Laboratório de Histopatologia do Departamento de Veterinária da Universidade Federal de Viçosa (UFV). Na avaliação microscópica 
descritiva, foram considerados a presença e o tipo de tecido no defeito e na interface.

\section{RESULTADOS E DISCUSSÃO}

$\mathrm{Na}$ avaliação histológica aos oito dias, verificouse, no grupo GI, tecido de granulação, presença de matriz orgânica não mineralizada nas bordas do defeito crítico e proliferação óssea a partir do periósteo ulnar em direção ao defeito. Já no GII, além do tecido de granulação, também se observou formação de tecido ósseo de aspecto trabecular, sobre o qual havia proliferação endosteal com células osteoblásticas (Fig. 1).

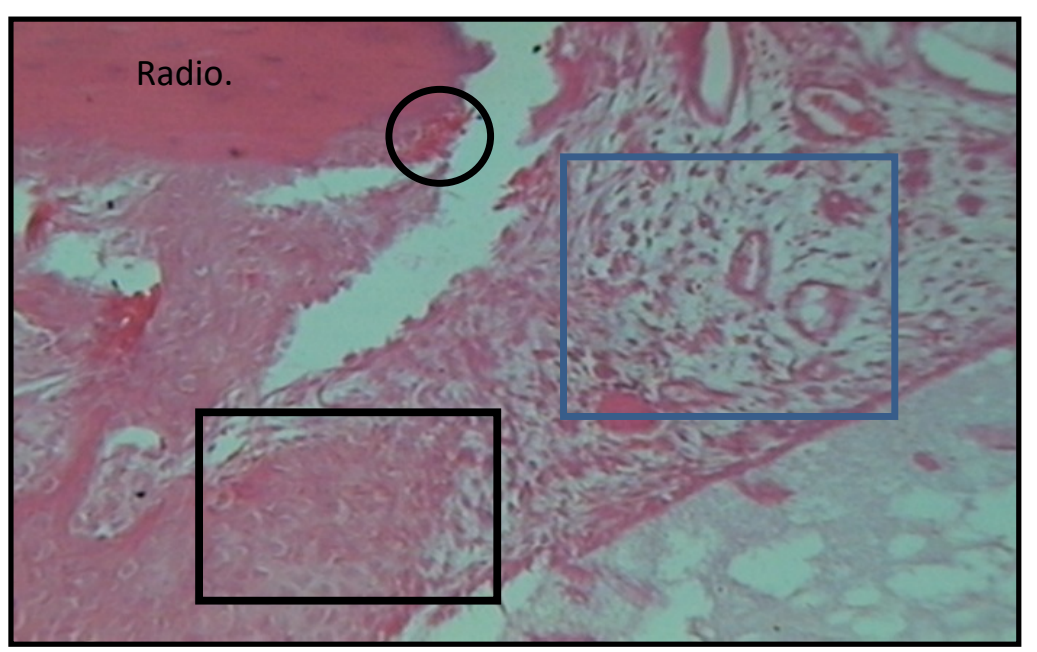

Figura 1. Fotografia de microscopia óptica aos oito dias. Observa-se tecido de granulação (quadrado azul), assim como presença de matriz orgânica não mineralizada nas bordas do defeito crítico (círculo preto); há formação de tecido ósseo de aspecto trabecular, Observa-se proliferação endosteal com células osteoblásticas (quadrado preto) (hematoxilina-eosina, 4x).

Segundo Borges (1998) e Fehlberg (2001), em todo processo de reparação óssea, desenvolve-se inicialmente um tecido de granulação no foco da lesão. No GIII, nesse mesmo tempo, foram observados os seguintes achados na histologia: além da presença do tecido de granulação, o defeito também estava preenchido por tecido fibroso e, em alguns casos, com restos de fibras musculares e as bordas da ostectomia ainda evidentes. Esses achados foram já mencionados na literatura em estudos semelhantes (Borges, 1998; Fehlberg, 2001; Vital et al., 2006).

Aos 15 dias, observou-se, histologicamente no GI, formação de tecido ósseo imaturo entremeado nos grânulos da cerâmica, com proliferação osteoblástica intensa, assim como resposta hiperplásica do periósteo ulnar. No GII era evidente a formação de tecido ósseo, assim como a osteointegração desse novo tecido ósseo com as bordas do defeito, presença de túneis vasculares no interior do implante, bem como pequenos focos cartilaginosos no centro do defeito (Fig. 2).
A presença de ninhos cartilaginosos desorganizados entremeando o implante pode ser explicada pelo grande tamanho do defeito. Esse tipo de formação óssea foi descrito por Webb e Tricker (2000) e Flach et al. (2002). Já no GIII (grupo controle), ainda havia presença de tecido de granulação e de tecido conjuntivo fibroso, angiogênese acentuada e escassa presença de osteoclastos, como descrito por Borges (1998), Borges et al. (2000), Vital et al. (2006), Lobo et al. (2009), Lobo e Arinzeh (2010) e Lobo (2011).

Aos 30 dias, verificou-se, nos animais do GI, a presença de matriz óssea não mineralizada (osteoide) e de osteoblastos ativos adjacentes aos extremos proximais e distais do rádio, indicando integração do implante ao osso receptor. Todavia, era evidente a presença da cerâmica e de tecido fibroblástico, assim como acentuada angiogênese. Havia também presença de tecido ósseo imaturo de aspecto trabecular. Nos animais do GII, observou-se presença significativa de tecido ósseo imaturo, com numerosas células osteoblásticas. Ocasionalmente, observou-se 


\section{Aristizabal et al.}

presença de fibras musculares, possivelmente originadas de células-tronco provenientes da medula óssea ou do tecido adjacente. Também foi evidente a presença de vasos sanguíneos de grande calibre (Fig. 3), o que está de acordo com o mencionado por Vital et al. (2006). No GIII, verificou-se que o crescimento do tecido ósseo neoformado a partir das bordas da ostectomia era pouco e, no defeito, foi observada a presença de tecidos fibroso, adiposo e de fibras musculares, como descrito e relatado por Lobo et al. (2009), Lobo e Arinzeh (2010) e Lobo (2011).

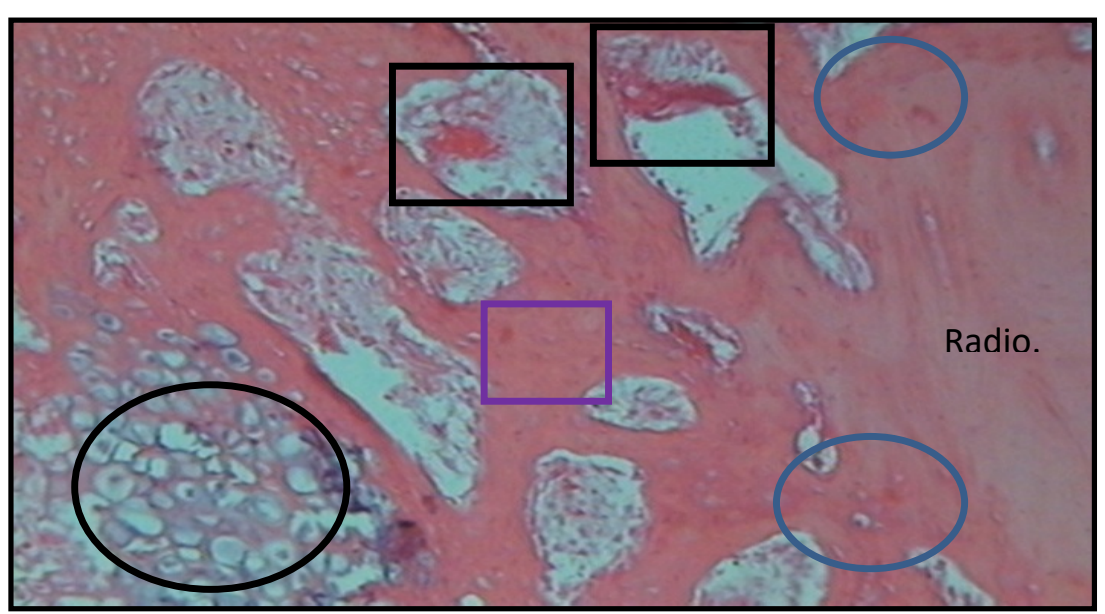

Figura 2. Fotografia de microscopia óptica aos 15 dias, animal pertencente ao grupo GII. Observa-se evidente formação de tecido ósseo (quadrado roxo), osteointegração na interface do defeito (círculos azuis), presença de túneis vasculares no interior do implante (quadrados pretos), assim como pequenos focos cartilaginosos no centro do defeito (círculo preto), (hematoxilina-eosina, 10x).

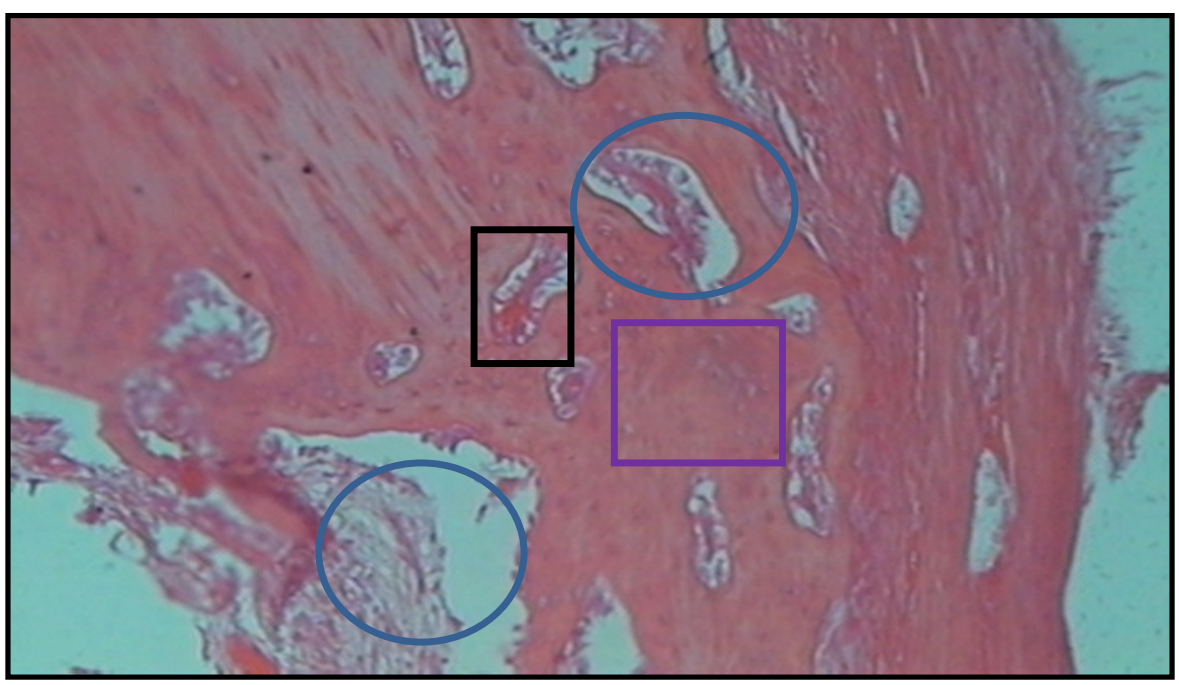

Figura 3. Fotografia de microscopia óptica aos 30 dias, GII. Observa-se maior presença de tecido ósseo imaturo (quadrado roxo), com numerosas células osteoblásticas, presença da cerâmica no local do implante (círculos azuis), assim como vasos sanguíneos de grande calibre (retângulo preto) (hematoxilina-eosina, 10x).

Aos 45 dias, verificou-se, nos animais dos grupos GI e GII, preenchimento da falha, ainda com presença de pequenos focos do material cerâmico no defeito. Havia numerosas células osteoblásticas sobre a superfície do tecido osteoide adjacente às bordas da ostectomia, indicando osteointegração, Nesse tempo, a evolução do GII era melhor ao ser comparada 
com a do GI. (Fig. 4). No GIII, havia presença mais acentuada de tecidos fibrocartilaginoso, adiposo e muscular em relação aos 30 dias.

Aos 60 dias, foi observada, em dois animais do GI, formação mínima de tecido osteoide, principalmente no extremo proximal do defeito, e presença de grânulos da cerâmica. Nos demais animais, na interface ostectomia/implante, havia evidente formação de novo tecido ósseo, assim como a presença de centros de ossificação. Nos animais do GII, houve maior formação e crescimento de tecido ósseo do que no grupo GI, presença de pequenos focos cartilaginosos, da cerâmica e de tecido conjuntivo ao redor dos grânulos do implante (Fig. 5). Já no grupo GIII, observou-se maior evolução do processo em relação aos 30 dias, com maior substituição de tecido cartilaginoso por tecido ósseo, como já relatado na literatura (Doige, 1990; Webb e Tricker, 2000; Doblare et al., 2004; Samuelson, 2007; Lobo et al. (2009), Lobo e Arinzeh (2010) e Lobo (2011).

\begin{abstract}
A formação óssea era mais evidente nos grupos tratados, nos quais o osso apresentava trabéculas mais espessas, tendendo a osso compacto, o que mostra a característica osteocondutora da cerâmica de hidroxiapatita e seu efeito favorável na reparação óssea (Fig. 5), como já mencionado por Oonishi et al. (1997), Borges et al. (2000) e Vital et al. (2006). Esses achados foram corroborados pelas análises de $\mathrm{MEV}$ nos três grupos avaliados, onde se observarm as características mostradas na avaliação por microscopia óptica. Verifica-se presença de tecido osteoide ao redor dos grânulos da biocerâmica, preenchendo a totalidade do defeito, bem como evidente formação de ósteons primários e estruturas semelhantes a osteócitos e osteoblastos, nos grupos tratados (Fig. 6 A e B). Nos animais do GIII, foi observado tecido neoformado, mas com presença de lacunas vazias distribuídas no defeito crítico (Fig. 6 C).
\end{abstract}

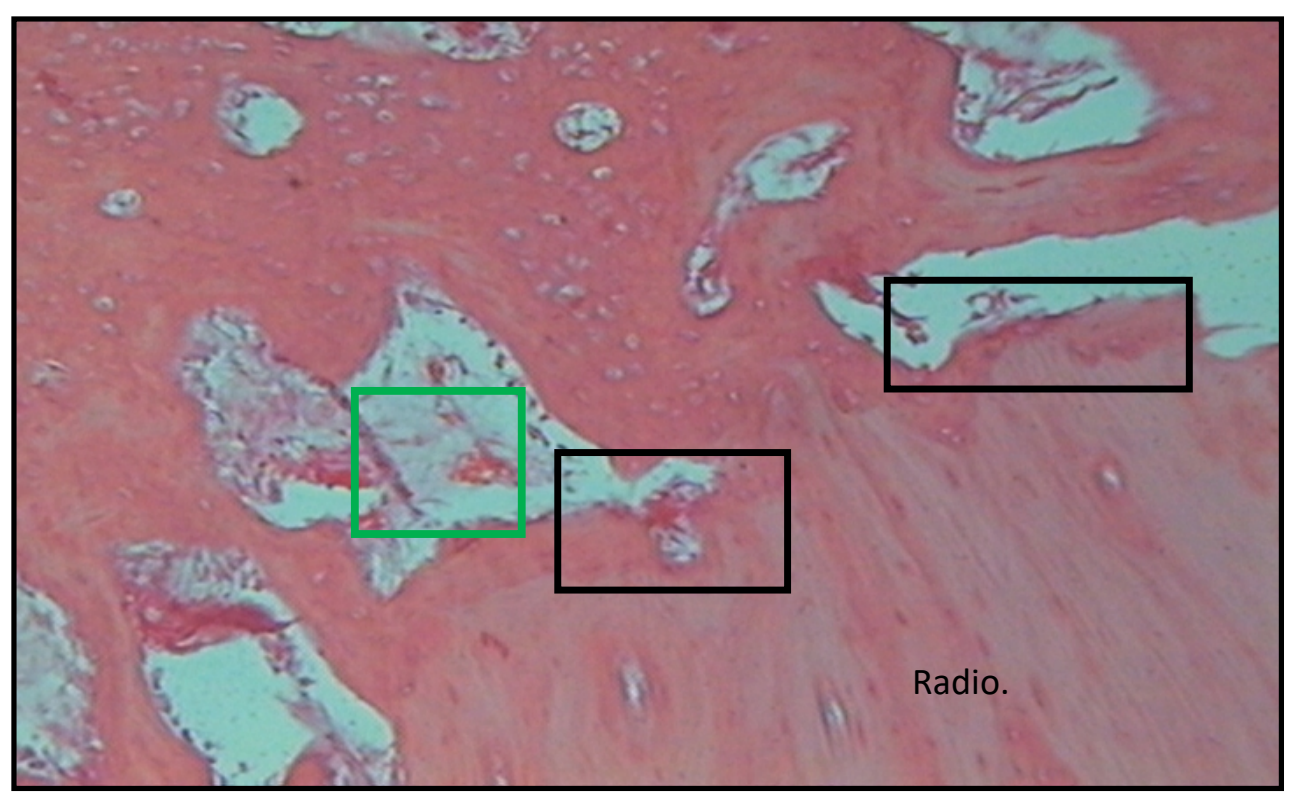

Figura 4. Fotografia de microscopia óptica aos 45 dias, GII. Observa-se evolução do preenchimento da falha, ainda com presença de pequenos focos do material cerâmico no defeito (quadrado verde), numerosas células osteoblásticas sobre a superfície do tecido osteoide adjacente às bordas, indicando osteointegração (quadrados pretos). Essas observações foram semelhantes para os GI e GII (hematoxilinaeosina, 10x). 


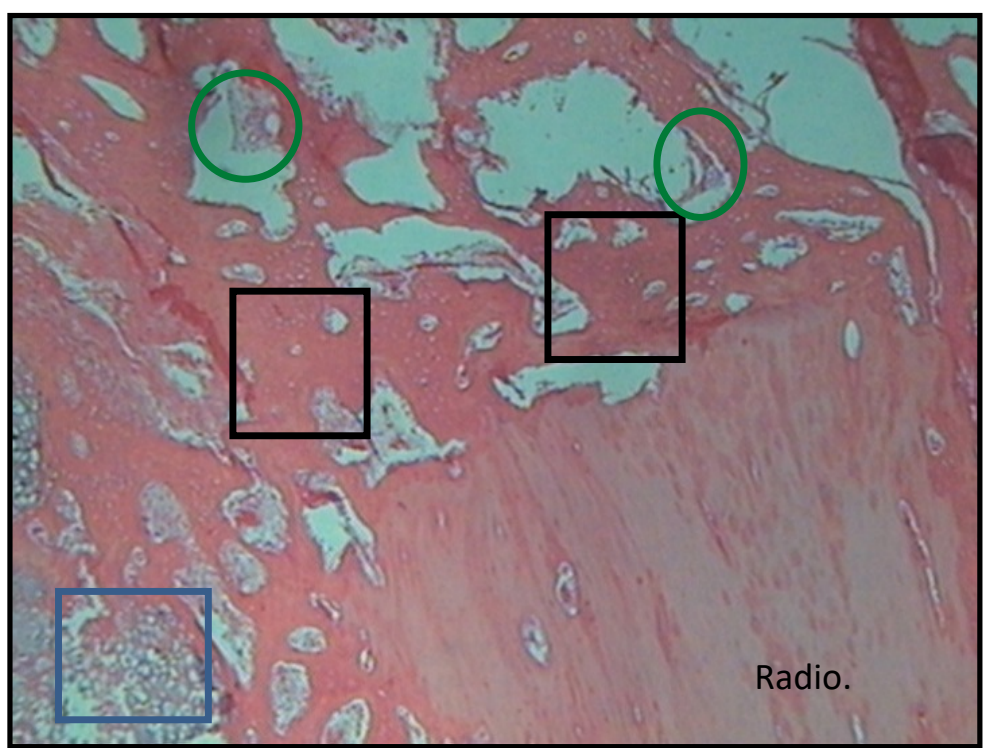

Figura 5. Fotografia de microscopia óptica aos 60 dias, grupo GII. Observou-se maior formação e crescimento de tecido ósseo (quadrado preto) do que no grupo GI, presença de pequenos focos cartilaginosos (quadrado azul), assim como da cerâmica (círculos verdes) e tecido conjuntivo ao redor dos grânulos do implante (hematoxilina-eosina, 10x).
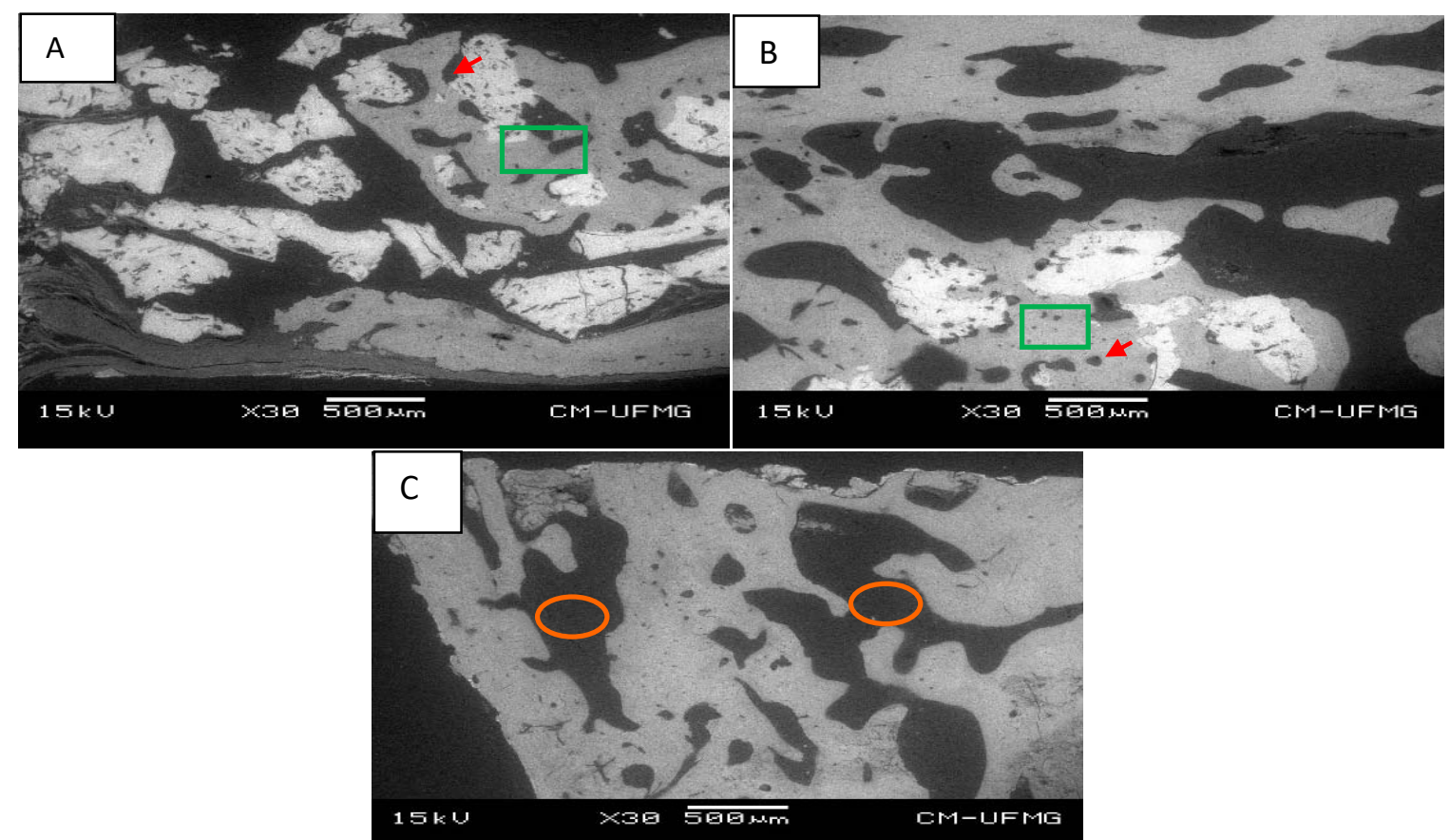

Figura 6. Fotomicrografias de microscopia eletrônica de varredura aos 60 dias após a implantação da biocerâmica macromicro porosa em defeito crítico do rádio de coelho evidenciando o crescimento do tecido ósseo. (A) grânulos de biocerâmica de absorção lenta: observa-se o tecido ósseo neoformado ao redor (quadrado verde) dos grânulos e formação de ósteon primário (seta vermelha); (B) grânulos de biocerâmica de absorção moderada evidenciando também o crescimento de tecido ósseo ao redor dos grânulos de biocerâmica (quadrado verde); (C) grupo controle negativo: observam-se as lacunas dentro do tecido ósseo neoformado (círculos laranja). 


\section{Avaliação histológica...}

Aos 90 dias, verificou-se, na avaliação histológica, nos animais do grupo GI, presença de tecido ósseo maduro, osteointegração do implante e presença de grânulos da cerâmica. Apenas um animal do GI apresentava discreto atraso na formação de tecido ósseo no defeito. Já nos animais do GII, foi observada maior evolução do processo com maior quantidade de tecido ósseo maduro em relação ao GI, caracterizado por presença de ósteons secundários e grandes vasos sanguíneos, ainda com presença de grânulos da cerâmica (Fig. 7), semelhante ao descrito por Samuelson et al. (2007)

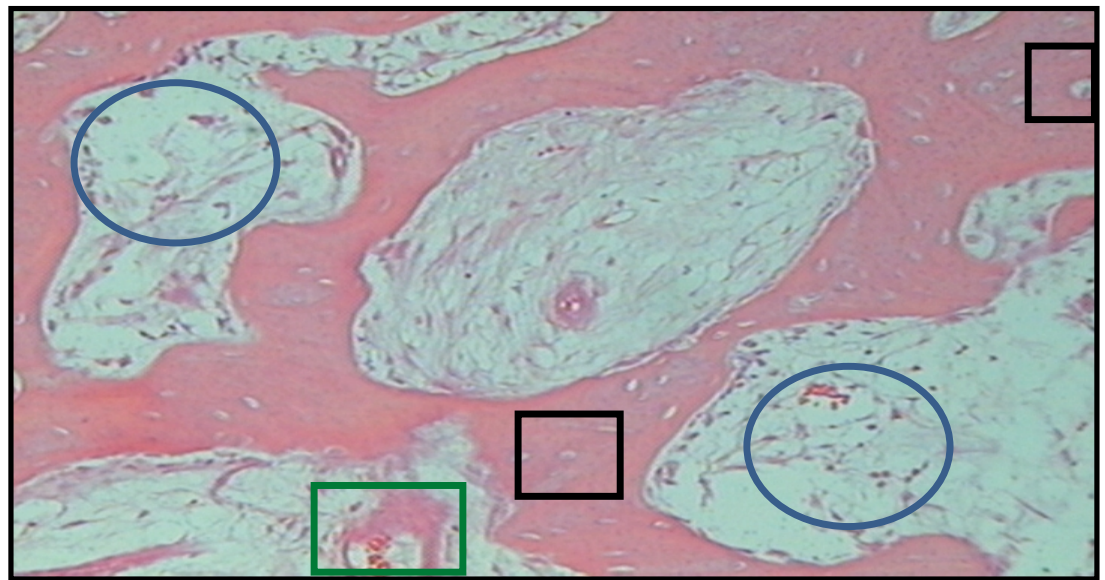

Figura 7. Fotografia de microscopia óptica aos 90 dias, grupo GII. Observa-se presença de tecido ósseo maduro, caracterizado por ósteons secundários (quadrado preto) e grandes vasos sanguíneos (quadrado verde), ainda com presença de grânulos da cerâmica (círculos azuis) (hematoxilina-eosina, 10x).

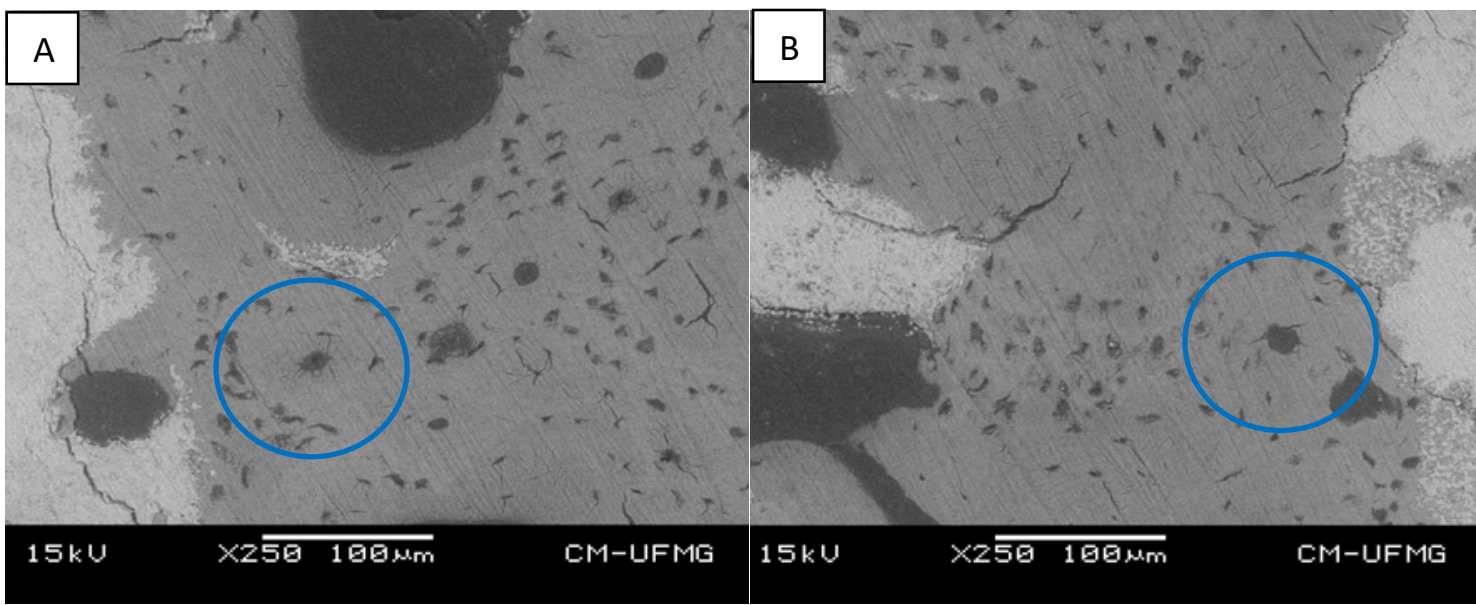

Figura 8. Fotomicrografias de microscopia eletrônica de varredura aos 90 dias após a implantação da biocerâmica macromicro porosa no defeito crítico do rádio de coelho. $(\mathrm{A}, \mathrm{B})$ biocerâmica de absorção lenta e moderada: observa-se o tecido ósseo neoformado maduro, com presença de ósteons secundários (círculo azul). 
Aos 120 dias, na avaliação histológica, verificouse no GI presença de osso compacto, presença de cerâmica no defeito, porém em menor quantidade quando comparada com os outros tempos. No GII, havia tecido ósseo compacto bem diferenciado preenchendo a totalidade do defeito. Em um animal, foi observado que o osso formado era semelhante ao osso receptor, com presença de ósteons secundários, sendo evidentes os sistemas de Havers. No GIII, observou-se regeneração óssea, porém menos desenvolvida quando comparada aos grupos GI e GII. O processo de reparação óssea nos grupos tratados mostrou-se mais adiantado do que no grupo controle até os 120 dias. Esse fato reforça a afirmação de vários autores, como Oonishi et al. (1997), Rezende et al. (1998), e Legeros (2003, que atribuem ao efeito osteocondutor da hidroxiapatita a qualidade de favorecedor da regeneração óssea, fato demonstrado neste estudo (Fig. 9 A e B). As avaliações de microscopia eletrônica de varredura evidenciaram maior proporção de tecido ósseo maduro e presença de ósteons secundários, o que confirma os achados nas avaliações histológicas nesse mesmo período de tempo (Fig. 10 A e B).
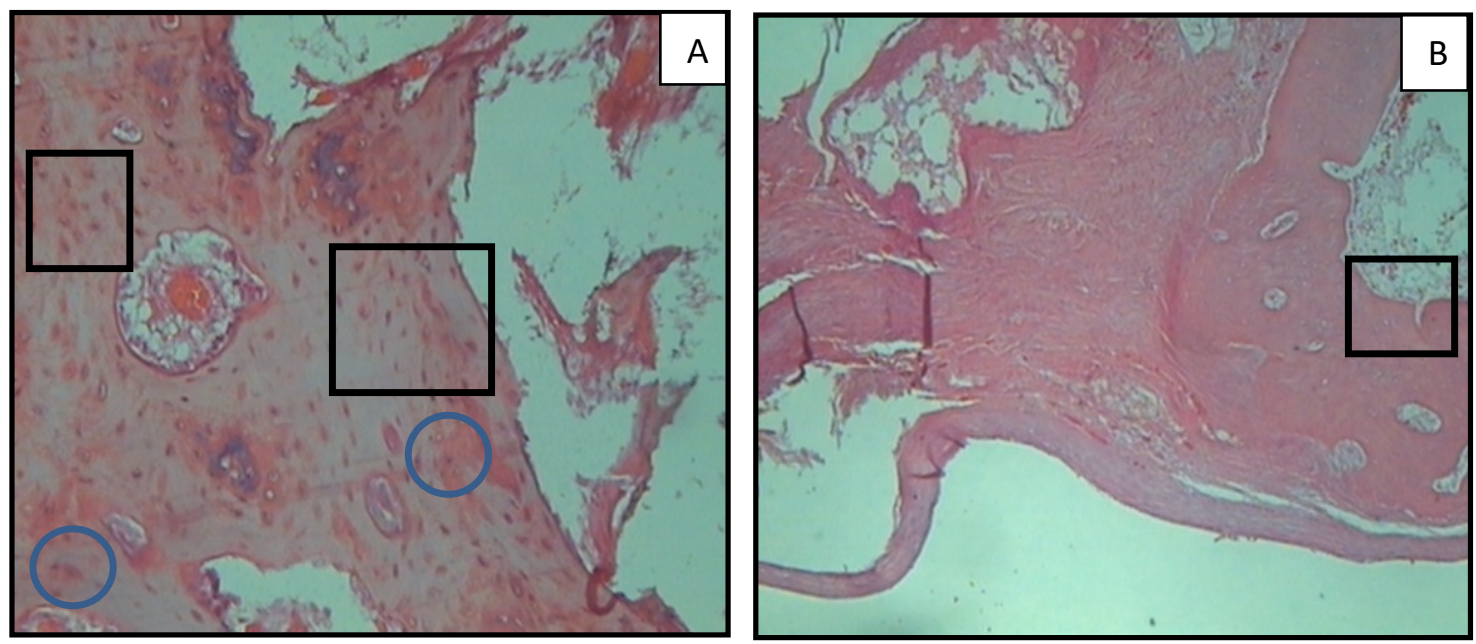

Figura 9. Fotografias de microscopia óptica aos 120 dias. (A) observa-se tecido ósseo compacto bem diferenciado preenchendo a totalidade do defeito (quadrados pretos), com presença de ósteons secundários (círculos azuis), sendo evidentes os sistemas de Havers (10x). (B) controle: observa-se regeneração óssea, porém menos desenvolvida quando comparada aos grupos tratados (quadrado preto) GI e GII (hematoxilina-eosina, 4x).

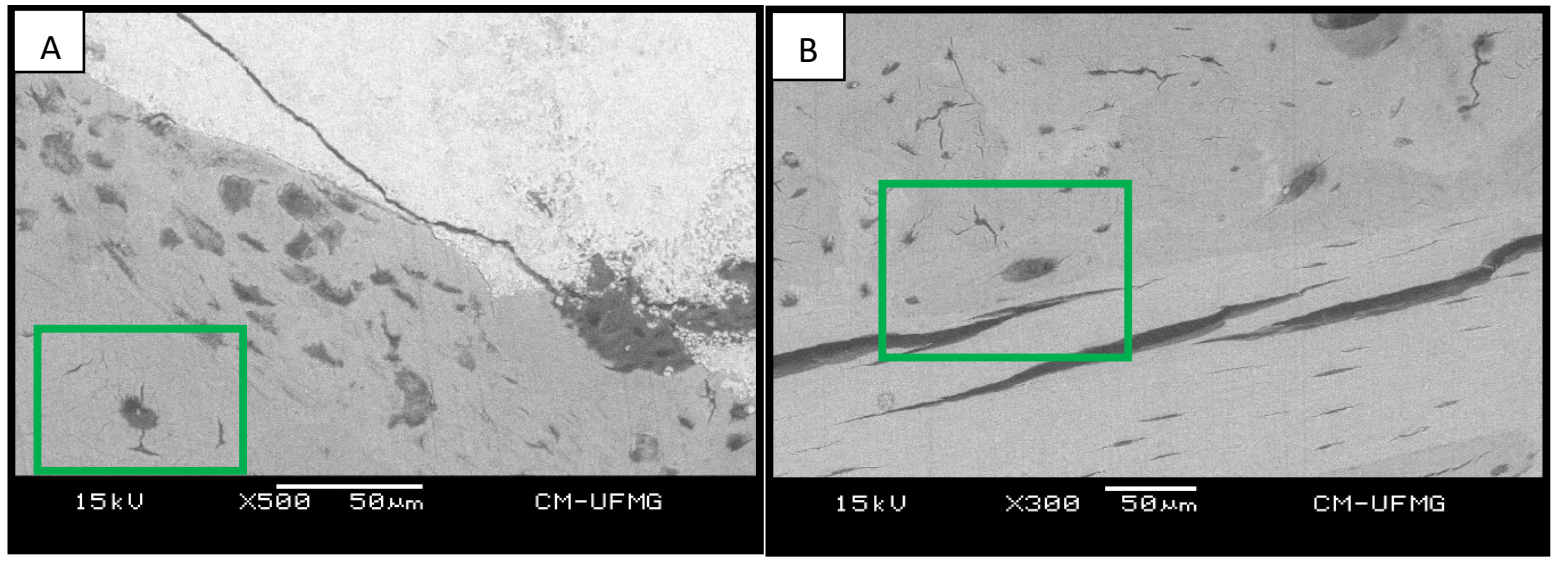

Figura 10. Fotomicrografias de microscopia eletrônica de varredura aos 120 dias após a implantação da biocerâmica macromicro porosa no defeito crítico do rádio de coelho. $(\mathrm{A}, \mathrm{B})$ biocerâmica de absorção lenta e moderada: observa-se a presença de tecido ósseo maduro, com presença de ósteons secundários (quadrado verde). 


\section{CONCLUSÕES}

Os resultados obtidos neste estudo permitem concluir que as biocerâmicas de fosfatos de cálcio nanoestruturadas micromacro porosas em grânulos de absorção lenta e moderada podem ser indicadas para o tratamento de defeitos ósseos críticos. As biocerâmicas permitem um tipo de crescimento ósseo direto, por meio da formação de um tecido fibrovascular, diferenciação e migração ao local de células osteoblásticas, com síntese de tecido osteoide, e a maturação óssea ocorre mais precocemente quando se emprega a cerâmica de absorção moderada.

\section{REFERÊNCIAS}

BETZ, R.R. Limitations of autografts and allograft: new synthetic solutions. Orthopedics, v.25, p.561-570, 2002.

BIOCERAMICA para reconstrução óssea. Belo Horizonte: Einco, 2011. 13p. (Relatório Técnico).

BORGES, A.P.B. O efeito da hidroxiapatita sintética na regeneração óssea de defeito provocado experimentalmente no terço proximal da tíbia de cães: estudo clínico-cirúrgico, radiológico e histológico por microscopia de luz e microscopia eletrônica de retrodisperção. 1998. 112f. Tese (Doutorado) - Escola de Veterinária, Universidade Federal de Minas Gerais, Belo Horizonte, MG.

BORGES, A.P.B.; REZENDE, C.M.F.; RIBEIRO, M.F.B. et al. Hidroxiapatita sintética (HAP-91) como substituto ósseo em defeito experimental provocado no terço proximal da tíbia em cão: aspectos à microscopia eletrônica de transmissão. Arq. Bras. Med. Vet. Zootec., v.52, p.616-620, 2000.

CAPLAN, A.I.; GOLDBERG, V.M. Principles of tissue engineered regeneration of skeletal tissues. Clin. Orthop. Relat. Res. 1999; v.367, p.12-16.

DOBLARE, M.; GARCIA, J.M.; GOMEZ, M.J. Modelling bone tissue fracture and healing: a review. Eng. Fract. Mech., v.71, p.1809-1840, 2004.

DOIGE, C. Sistema esquelético. In: THOMSON, R.G. Patologia veterinária especial. São Paulo: Manole, 1990. cap.11, p.531-578.
FEHLBERG, A.F. Hidroxiapatita sintética na regeneração de falha óssea provocada em fratura do tércio intermédio de tíbia imobilizada pela fixação percutânea em cães. 2001. 42f. Tese (Mestrado em Medicina Veterinária). Universidade Federal de Viçosa. Viçosa, MG.

FLACH, D.M.; GORGOZINHO, K.B.; PRAZERES, M.N. et al. Regeneração óssea em cães e gatos. 2002. Disponível: $<\mathrm{http}$ ///www.uff.org.br/regeneracao-ossea.htm>

GAO, T. J.; LINDHOM, B.; KOMMONEN, P.; RAGNI, P. et al. Microscopic evaluation of bone-implant contact between hydroxyapatite, bioactive glass and tricalcium phosphate implanted in sheep diaphyseal defects. Biomaterials, v.16, p.1175-1179, 1995.

LEGEROS, R.Z. Calcium phosphate- based osteoinductive materials. Chem. Rev., v.108, p.4742-4753, 2008.

LEGEROS, R.Z.; LIN, S.; ROHANIZADEH, R. et al. Biphasic calcium phosphate bioceramics: preparation, properties and applications. $J$. Mater. Sci. Mater. Med., v.14, p.201-209, 2003.

LOBO, S.E. Modulação do fenótipo de células tronco através de biocerâmicas de fosfatos de cálcio. 2011. 129f. Tese (Doutorado) - Escola Paulista de Medicina, Universidade Federal de São Paulo, SP.

LOBO, S.E.; WYKROTA, F.H.; OLIVEIRA, A.C. et al., Quantification of bone mass gain in response to the application of biphasic bioceramics and platelet concentrate in criticalsize bone defects. J. Mater. Sci. Mater. Med., v.20, p.1137-1147, 2009.

LOBO, S.E; ARINZEH, T.L. Biphasic calcium phosphate ceramics for boné regeneration and tissue engineering applications. Materials, v.3, p.815- 826, 2010.

OLIVEIRA, R.S.; BRIGADO, R.; MADUREIRA, J.F. et al. Reconstruction of a large complex skull defect in a child: a case report and literature review., Child. Nerv. Syst., v.23, p.1097-1102, 2007.

OONISHI, H.; KUSHITANI, S.; YASUKAWA, E. et al. Particulate bioglass compared with hydroxyapatite as a bone graft substitute. Clin. Orthop. Relat. Res., v.334, p.316-325, 1997. 
PIERMATTEI, D.L.; FLO, G.L. Handbook of small animal orthopedics and fracture treatment. 3.ed. Philadelphia: Saunders, 2004. The stifle joint: p.516-580.

REZENDE, C.M.F.; BORGES, A.P.B.; BERNIS, W.O. et al. Aspectos clinico-cirurgicos e radiográficos da hidroxiapatita sintética na diáfise distal da tíbia de cães. Arq. Bras. Med. Vet. Zootec., v.50, p.537-545, 1998.

RUMPEL, E., WOLF, E., KAUSCHKE, E. et al. The biodegradation of hydroxyapatite bone graft substitutes in vivo. F. Morph., v.65, p.43-48, 2006.

SAMUELSON, D.A. Cartilage and bone. C.6. In: . Texbook of veterinare histologe. [Philadelphia]: Saunders Elsevier, 2007. p.100129.
SHIMAZAKI, K.; MOONEE, V. Comparative study of porous hydroxyapatite and tricalcium phosphate as bone substitute. J. Orthop. Res., v.3, p.301-310, 1985.

VITAL, C.C.; BORGES, A.P.; FONSECA C.C. et al. Biocompatibilidade e comportamento de compósitos de hidroxiapatita em falha óssea na ulna de coelhos. Arq. Bras. Med. Vet. Zootec., v.58, p.175-183, 2006.

WEBB, J.C.J.; TRICKER, J. Bone biology. a review of fracture healing. Curr. Orthop., v.14, p.457-463, 2000.

WYKROTA, L.L.; WYKROTA, F.H.L.; GARRIDO, C.A. Long-term bone regeneration in large human defects using calcium-phosphate particulate. In: DAVIES, J.E. (Ed.). Bone engineering. Toronto: Square incorporated, 2000. p.516-525. 